\title{
Insertarse, adaptarse y construir: Participación del exilio chileno en las universidades estatales costarricenses a partir de 1974
}

Fitting, Adapting and Building:

\section{Participation of Chilean exiles in Costa Rican State Universities}

Inserir, adaptar e construir: participação do exílio chileno nas universidades estatais da Costa Rica a partir de 1974

\author{
Marcela Ramírez-Hernández \\ Académica investigadora \\ Universidad Nacional \\ Costa Rica \\ Recibido:15/11/2019 - Aceptado:17/01/2020
}

Profesionales de diversas ramas ocupacionales y disciplinas fueron expulsados de Chile como consecuencia de las políticas represivas y del desmantelamiento del Estado durante la dictadura de Augusto Pinochet. Costa Rica, como país receptor de este flujo migratorio contó, entre las décadas de 1970 y 1980, con la presencia de más de un centenar de profesionales chilenos, quienes encontraron en las universidades locales un campo fértil para el fortalecimiento y desarrollo de sus habilidades. Este artículo pretende reconocer sus perfiles socio profesionales

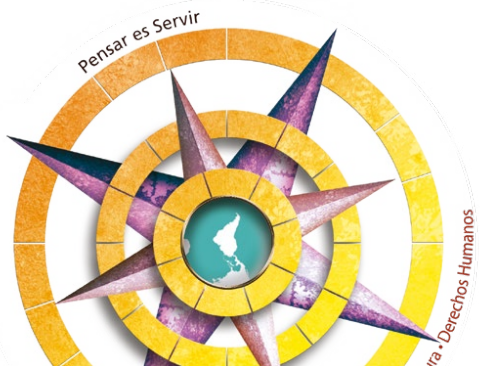

y recorridos por la academia, empleando como fuentes los archivos universitarios y las entrevistas personales. A partir de la indagación se identificó que, a través del quehacer académico, varias de estas personas generaron significativos 
aportes desde la producción intelectual, la innovación temática, la administración universitaria, la fundación de carreras o desde el enriquecimiento metodológico y teórico a múltiples áreas del saber.

Palabras clave: Exilio chileno, migración, cultura, educación superior, redes sociales, pensamiento latinoamericano.

\begin{abstract}
Professionals from diverse occupational branches and disciplines were expelled from Chile as a result of repressive policies and the dismantling of the State during the dictatorship of Augusto Pinochet. Costa Rica, as a receiving country of this migratory flow, counted among the 1970s and 1980s, with the presence of more than a hundred Chilean professionals, who found in the local universities a fertile field for the strengthening and development of their skills. This article seeks to recognize their socio-professional profiles and their journeys through academia, using university archives and personal interviews as sources. From the investigation it was identified that, through the academic work, several of these people generated significant contributions from intellectual production, thematic innovation, university administration, the foundation of careers or from methodological and theoretical enrichment to multiple areas of knowledge.
\end{abstract}

Keywords: Chilean exile, migration, culture, higher education, social networks, Latin American thought

Resumo

Profissionais de vários ramos profissionais e disciplinas foram expulsos do Chile como resultado de políticas repressivas e do desmantelamento do Estado durante a ditadura de Augusto Pinochet. A Costa Rica, como país receptor deste fluxo migratório, contou entre os anos 70 e 80 com a presença de mais de uma centena de profissionais chilenos, que encontraram nas universidades locais um campo fértil para o fortalecimento e desenvolvimento das suas competências. Este artigo procura reconhecer os seus perfis socioprofissionais e as suas viagens através do meio académico, utilizando como fontes arquivos universitários e entrevistas pessoais. A partir da investigação identificou-se que, através do trabalho académico, várias destas pessoas geraram contribuições significativas da produção intelectual, da inovação temática, da administração universitária, da fundação de carreiras ou do enriquecimento metodológico e teórico para múltiplas áreas do conhecimento.

Palavras chave: Exílio chileno, migração, cultura, educação superior, redes sociais, pensamento latino-americano

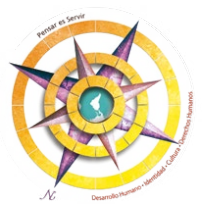


En la década de 1970, Costa Rica fue testigo de la confluencia de múltiples exilios provenientes de otros países latinoamericanos. Entre los flujos migratorios de mayor impacto dentro del acontecer local, encontramos el exilio chileno que influyó significativamente en los campos de la cultura y la educación costarricense. En torno al último aspecto, este artículo se enfocará en reconocer el trabajo realizado y el legado de esta comunidad suramericana a las universidades en las que tuvieron mayor presencia: la Universidad de Costa Rica (UCR) y la Universidad Nacional (UNA).

Para un acercamiento preliminar al quehacer de los chilenos, se exploran las disciplinas y espacios de incursión en los que generaron colaboraciones y emprendimientos trascendentales, cuya articulación estuvo favorecida por la intervención de factores atinentes tanto al contexto costarricense, como a la historia de vida y trayectoria profesional de protagonistas chilenos.

\section{Chile y Costa Rica en los años setenta: Tejidos contextuales}

Las razones por las que chilenos y chilenas encontraron en suelo costarricense un terreno fértil para establecerse son de índole histórico. En este sentido, existen dos dimensiones intrínsecamente entrelazadas: una de larga data, articulada a través de vínculos pedagógicos e intelectuales establecidos desde finales del siglo XIX y otra, que se explicará en este texto, asociada con los contextos sociopolíticos de Costa Rica y Chile de la década de 1970.

Para ello, en un primer momento se acota brevemente como un elemento fundamental, el acontecer local en torno al desarrollo de la educación superior, pues el ambiente sociocultural en la Costa Rica de este decenio estuvo definido por la apertura de nuevos centros universitarios.

Desde la década de los cuarenta, la UCR fue la única institución de educación superior en el país, hasta que en 1971 se creó el Instituto Tecnológico Costarricense (TEC), posteriormente, en 1973 surgió la UNA, fundada sobre los cimientos de la Escuela Normal con el objetivo principal de especializarse en carreras pedagógicas, desde la perspectiva de la Universidad $\mathrm{Ne}$ cesaria ${ }^{1}$ y finalmente, en 1977 , se

1 Según Benjamín Núñez, la idea de Universidad Necesaria adoptada en la fundación de la UNA, señala la trascendencia de las instituciones de educación superior, no solo en la transmisión y generación de conocimiento, sino como instrumentos para alcanzar el 
instauró la Universidad Estatal a Distancia (UNED).

El arribo de los exiliados coincidió con la coyuntura de ordenamiento institucional en la UCR y la UNA. En el caso de la primera, atravesaba por reestructuraciones administrativas y la consolidación de nuevas perspectivas sobre la autonomía y el quehacer universitario (Camacho, 2012), mientras la UNA, en su etapa fundacional requería de un amplio equipo de expertos para la creación de departamentos, programas de estudio, la administración, la docencia e investigación.

\section{Los chilenos en la academia costarricense: Motivos del exi- lio y sus perfiles profesionales}

La presencia del exilio chileno en las universidades se caracterizó por la heterogeneidad de sus perfiles, así como por la diversidad de ámbitos a los que aportaron, pasando por la cultura, la teorización, la enseñanza y la administración. Algunos se proyectaron como artistas y literatos más allá de las aulas universitarias,

bienestar social. Para esto, proponía articular programas basados en la racionalidad instrumental, lo que significaba estructurar el quehacer académico en función de las necesidades de la sociedad costarricense en sus dimensiones políticas, culturales y económicas, en aras del desarrollo y el fortalecimiento de la democracia (Núñez, 1974). pero mantuvieron en común la academia como su espacio formal de producción y de enseñanza.

Tal variedad se manifestó también, en el hecho de que, al momento de arribar cada uno atravesaba por etapas distintas de sus vidas personales y profesionales, hecho que contribuyó a trazar sus posibilidades de aportación. Para ilustrar, algunos llegaron con carreras consolidadas o en formación -como los geógrafos Juan Humberto Cevo y Eusebio Flores, poseedores de gran bagaje en el ejercicio universitario o el artista y arquitecto Juan Bernal Ponce-. Pero otros, emprendieron su ruta por la academia en Costa Rica, ya fuese porque en Chile se desenvolvieron en otro tipo de instituciones, mientras algunos hicieron sus estudios en las universidades locales y desarrollaron sus carreras en ellas.

No obstante esta variedad en sus perfiles profesionales, los motivos que los llevaron a salir de Chile involucran los efectos directos de las políticas ejecutadas por la dictadura que ocasionaron un rápido deterioro de la institucionalidad estatal y altas tasas de desempleo. En general, un panorama de inestabilidad económica y política que tuvo entre sus escenarios más ejemplares, las universidades públicas, entidades que

198 Insertarse, adaptarse y construir: Participación del exilio chileno en las universidades estatales costarricenses a partir de 1974 Marcela Ramírez-Hernández

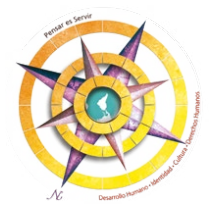


fungieron un rol social neurálgico durante los gobiernos de Eduardo Frei (1964-1970) y Salvador Allende (1970-1973).

Bajo estos mandatos, los recintos fueron herramientas centrales para la difusión ideológica y la ejecución de programas sociales. Dicho rol se acentuó durante la presidencia de Allende, pues las universidades eran concebidas como espacios dedicados al estudio de la realidad, generadores de alternativas transformadoras, confiriéndoles un matiz profundamente politizado (Cevo, 2016; Romero, 2017). Estudiantes y profesores eran militantes partidistas o simpatizantes al menos, de los grupos izquierdistas, lo que marcó el enfoque de varias disciplinas como el teatro, la geografía, la sociología y la psicología, entre otras (Garretón, 2005).

Con el golpe de Estado, los trabajadores universitarios experimentaron repentinamente la expulsión o la persecución, algunos incluso fueron detenidos. Desde el inicio de la dictadura, las instituciones educativas y culturales fueron el principal blanco del desmantelamiento del proyecto allendista, por ello, el sistema de educación superior fue totalmente desarticulado ${ }^{2}$. La Junta

2 La dictadura tomó medidas en las universidades dirigidas a "limpiarlas ideológicamente",
Militar intervino las universidades y cerró departamentos completos, apresó y desapareció a académicos y estudiantes sospechosos de estar vinculados con los partidos políticos aliados a la Unión Popular, además de destituir a decanos, directores, docentes y funcionarios administrativos, para nombrar en sus cargos a personas afines al nuevo régimen (Archivo Chile, 2005). Geógrafos, administradores, filólogos, psicólogos, filósofos y artistas ingresaron a Costa Rica luego de despidos o persecuciones por su militancia política o por ser simpatizantes del gobierno de Allende.

Por otra parte, las políticas para controlar totalmente las universidades impactaron con mayor fuerza a las ciencias sociales, la educación y la

\footnotetext{
expulsando a académicos, académicas y estudiantes que pudiesen estar asociados con los partidos políticos de izquierda. En un primer momento, decretó la Ley N. 50 del 2 de octubre de 1973, para el nombramiento de nuevos rectores encargados de renovar completamente el cuerpo docente y administrativo, así como intervenir, cerrar o renovar unidades académicas y proyectos de investigación. Posteriormente, en el lapso 1981-1989, se impulsó el plan definitivo para privatizar la educación y fragmentar completamente las universidades estatales a través de la Ley de Universidades de 1981 (Biblioteca del Congreso Nacional de Chile, 1 de octubre 1973; Garretón, 2005). Se ha identificado en los archivos institucionales de la Universidad Nacional y la Universidad de Costa Rica, un repunte en este periodo en la contratación de profesionales chilenos.
}

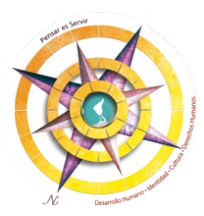

Insertarse, adaptarse y construir: Participación del exilio chileno 199 en las universidades estatales costarricenses a partir de 1974 
medicina. Garretón (2005) expone cifras que concuerdan con el patrón en las universidades costarricenses, en las que se detectó que un alto porcentaje de chilenos se ubicaron en las facultades de Humanidades y Ciencias Sociales y provenían en su mayoría de la Universidad de Chile.

Sumado a la situación anterior, la profundización del modelo neoliberal en Chile produjo el aumento en las tasas de pobreza y desempleo, a la vez que todas las instituciones fortalecidas durante el gobierno de Allende sufrieron políticas dirigidas a jibarizar sus estructuras internas y enfrentaron la persecución sistemática contra ciertos líderes y empleados. El caos produjo oleadas de migrantes económicos, como fue el caso de personas como Arturo Jofré Vartanián, exprofesor en la UTE y ex empleado de la Empresa Nacional de Electricidad S.A, o del biólogo Jorge Cabrera Peña que se movilizó con su familia hacia Guatemala y posteriormente a Costa Rica en aras de estabilidad laboral y proyección profesional (Comunicación personal, 24 de noviembre 2017).

\section{Características demográficas y profesionales}

Entre los académicos chilenos existen elementos diferenciadores de índole generacional, pero, además, de trayectoria. Generacionalmente, encontramos a un grupo que desarrolló sus labores o se formó en las universidades en el ambiente de la Reforma Universitaria que inició en 1967. Esto los dotó de una experticia y mirada política en torno a áreas como la gestión administrativa y los fines sociales de la educación superior, del que las universidades costarricenses obtuvieron beneficios directos.

Con estas características encontramos a los psicólogos Armando Campos Santelices y Dina Krauskopf, los geógrafos Eusebio Flores Silva, Juan Humberto Cevo Guzmán, Miguel Morales y Florencio Magallón; artistas como Julio Escámez, Juan Bernal Ponce y Sara Astica; a Gastón Gaínza y Helio Gallardo en las letras y la filosofía, así como médicos, sociólogos, biólogos, planificadores, matemáticos, entre otros. Este grupo mixto, compuesto por académicos y extrabajadores estatales es el más representativo numéricamente - abarcan más del $50 \%$ de los perfiles analizados - pero también el de mayor peso por la variedad y calidad de sus aportes.

Para Daniel Camacho, sociólogo costarricense que colaboró con la solidaridad hacia los exiliados, ese

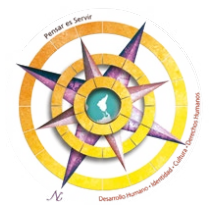


periodo de recepción de chilenos en las casas de estudio tuvo un carácter ambivalente, cuyas utilidades se tradujeron en el intercambio de conocimientos y el fortalecimiento de la educación superior. Desde una mirada retrospectiva, considera:

El país dichosamente se benefició de todo lo que ellos dieron y entre los profesores universitarios hubo algunos que incluso vegetaron, pero hay una cantidad considerable de gente de gran calidad que aportó mucho. Yo hace años decía en broma, que ése era el programa de cooperación de Pinochet con Costa Rica, mandarnos la mejor gente. (Comunicación personal, 30 de marzo 2017)

Otra característica es que la duración de su estancia fue variable, pues dependía de los motivos por los que estaban en Costa Rica y de las posibilidades de crecimiento profesional. De esta manera, hubo quienes fungieron temporalmente como asesores, mientras otros aprovecharon las universidades como una plataforma de salida hacia otros destinos, como, por ejemplo, la trabajadora social Teresa Quiróz Martin, quien se trasladó hacia Perú luego de nutrir su currículo con labores emprendidas en el país.
En relación con quienes provenían del sector público chileno, es válido afirmar que su ingreso a las universidades costarricenses fue favorecido por el contexto educativo. La experiencia forjada en su país de origen los presentó como buenos candidatos para la docencia universitaria, en un momento en el que la oferta local de especialistas en diversas disciplinas era relativamente reducida. Ejercieron en entidades estatales como el Ministerio de Educación, la Corporación de Fomento a la Producción (CORFO) y sus filiales, el Servicio Nacional de Salud, entre otros.

Varios funcionarios estatales o docentes de segunda enseñanza articularon una larga trayectoria académica. Destacaron Víctor Álvarez, médico veterinario en el Servicio Nacional de Salud en Chile; en Costa Rica, fue catedrático de la Escuela de Ciencias Agrarias de la UNA; la bióloga Ivette Inostroza, docente de segunda enseñanza en su país natal, laboró por dos décadas en la Escuela de Ciencias Biológicas de la UNA (ARH, UNA). En las sedes regionales, estuvo Félix Riveros, supervisor de direcciones para el Ministerio de Educación en Valparaíso; una vez en Pérez Zeledón, fue académico de la UNA durante 27 años en la sede de la Región Brunca (García, 7 de noviembre 1999). 
En un segundo grupo generacional, de menor representatividad numérica, están quienes llegaron siendo estudiantes, hombres y mujeres que se prepararon en las universidades costarricenses. Para el caso de la UNA, se han dedicado a disciplinas como la historia, la sociología y la antropología. Como muestra, los sociólogos Ana María Balbontín, José Daniel Cazanga y Cecilia Quezada y el historiador Mario Oliva Medina.

\section{Estrategias de inserción de los exiliados chilenos en las universidades}

En los cuatro años posteriores a 1973, tuvo un peso significativo la existencia de redes sociales en la inserción de los chilenos a los claustros universitarios. Para comprender adecuadamente la lógica operativa de dichos enlaces interpersonales, se indica que redes sociales nos refiere "a espacios de interacción social -del cual el tejido de la red da cuenta-que no implica que todos los individuos que participan en la red se conozcan ni compartan espacios de sociabilidad" (González, 2008, p. 27). A partir de esta lógica, reconocemos que efectivamente primó una dinámica en la que diversas personas cumplieron una función nodal para establecer conexiones estratégicas entre profesionales.
Los enlaces con políticos nacionales, así como con intelectuales "chilenoides" con puestos de autoridad, facilitaron la recepción y permanencia de chilenos en las universidades. En la UCR intelectuales y profesores -principalmente asociados con la izquierda política- fueron fundamentales en esta dinámica, mientras la presencia de Benjamín Núñez como rector fundador definió en buena medida la posición de la UNA con respecto al ingreso de suramericanos. Con el tiempo, se generaron otro tipo de redes en las que los mismos chilenos, una vez establecidos, recomendaron a sus pares para proyectos o en sustitución. También existieron otros entramados compuestos por representantes de partidos políticos asociados a grupos estudiantiles o sindicatos universitarios, que funcionaron como mediadores ante las unidades académicas (Cuenca, 20 de setiembre 2017).

En cuanto a la UNA, se reconoció que la Comisión Organizadora Ad Hoc y los directores de departamentos estimularon la contratación de extranjeros (Acta 33, 26 de junio 1973). Lo anterior tuvo el propósito de que, a través de ellos, se definiera un estatus de calidad en la formación profesional, pero, principalmente, captar a especialistas en disciplinas poco desarrolladas o aún incipientes, 
como la geografía o la planificación social, y aprovechar su experiencia en la conformación de departamentos y planes de estudio.

Como muestra, encontramos además que, en diciembre de 1973, el rector Núñez emprendió un viaje estratégico hacia Perú, Argentina y Chile, para establecer alianzas con universidades de la región e identificar potenciales colaboradores. En el último país, obtuvo seis hojas de vida: personas de disciplinas como salud pública, sociología, trabajo social, medicina y teatro, cada uno con una amplia trayectoria (Comisión Organizadora, acta 71, 20 de diciembre 1973). De estos candidatos, ninguno convino con la universidad -según se constató en el Archivo de Recursos Humanos- pero el suceso da cuenta del interés del jerarca en atraer a personal con experiencia y mantener abiertas las puertas institucionales a los exiliados.

En este punto, es necesario mencionar que, si bien en fechas paralelas o posteriores a las indicadas en las actas de la Comisión reclutaron a un vasto grupo de chilenos, las vías usuales de inserción eran por concursos públicos y la existencia de redes de solidaridad. En la UCR, en fechas posteriores a 1973, esas redes estuvieron constituidas alrededor de personajes como Carlos Monge Alfaro o Isaac Felipe Azofeifa, ambos ligados a agrupaciones solidarias y quienes respaldaron a varios profesores de esta nacionalidad.

Organizaciones surgidas al interior de la UCR como el Comité de Solidaridad con Chile creado en julio de 1974, fueron fundamentales en las redes sociales, pues algunos de sus miembros eran jerarcas administrativos o de facultad. Entre los integrantes estaban: Claudio Gutiérrez, rector de 1974 a 1981; el profesor Camacho, decano del Departamento de Ciencias del Hombre; Isaac Felipe Azofeifa, decano de Estudios Generales; Arnoldo Mora, vicedecano de la Facultad de Filosofía y Alfonso Trejos Willis, representante del Área de Salud en el Consejo Universitario. Por intermedio de ellos, se crearon plazas o se destinó presupuesto extraordinario para el nombramiento de chilenos, proceder que contó con el aval de la rectoría desde fechas previas a la conformación del comité (Camacho, comunicación personal, 30 de marzo 2017).

Se puntualiza que la constitución y dinámicas de dichas redes sociales no eran estáticas, si no que permanecían en transformación, en el sentido de que chilenos que recibieron apoyo por parte de costarricenses para 
establecerse laboralmente asumieron en etapas posteriores el rol de conectores facilitando a otros el ingreso a estos recintos. Por ejemplo, el arquitecto Bernal Ponce, al renunciar a su cargo docente en la UNA en agosto de 1974, recomendó a su amigo, el pintor Escámez Carrasco en sustitución (ARH, UNA). Este último fue académico de la Escuela de Artes y Comunicación Visual por más de 22 años.

\section{Permanecer para construir:} Aportes del exilio chileno a la UNA y la UCR

La herencia dejada por los chilenos en la educación superior es considerada desde esta investigación, ante todo, como colaboraciones, acciones emprendidas en colectivo con equipos de trabajo y casi nunca de manera individual. Así crearon, a partir de bases previamente establecidas epistemológicas o institucionales -, fortaleciendo perspectivas disciplinarias o ampliándolas, formulando proyectos y concretándolos con el apoyo de compañeros y compañeras que se nutrieron de su experiencia o que construyeron experiencia junto a ellos.

Sus aportes surgieron del trabajo académico, comprendido como el conjunto de acciones que abarcan la docencia, la investigación y la extensión, a través de las que les fue posible apropiarse, crear y reproducir conocimiento. Esto conllevó al diálogo entre pares, la reflexión y la generación de contribuciones, con alcances tanto dentro como fuera de los linderos de los centros universitarios (García y Ortiz, 2012) y lo que contempla, igualmente, labores afines a la administración universitaria.

\section{El recorrido de los chilenos por}

\section{la UNA desde su fundación a la actualidad}

La UNA recibió aproximadamente 89 funcionarios de esta nacionalidad, entre profesores y administrativos distribuidos en ocho facultades. En términos numéricos, la Facultad de Ciencias Sociales (FCS) encabezó la lista, patrón que se repitió en la UCR. Como se aprecia en el gráfico 1, el Centro de Investigación, Docencia y Extensión Artística (CIDEA) contó con la colaboración de dieciocho chilenos, algunos de ellos destacados pintores, grabadores y actrices portadores de un amplio bagaje.

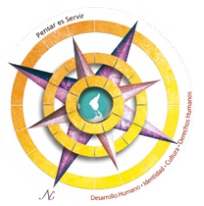




\section{Gráfico 1}

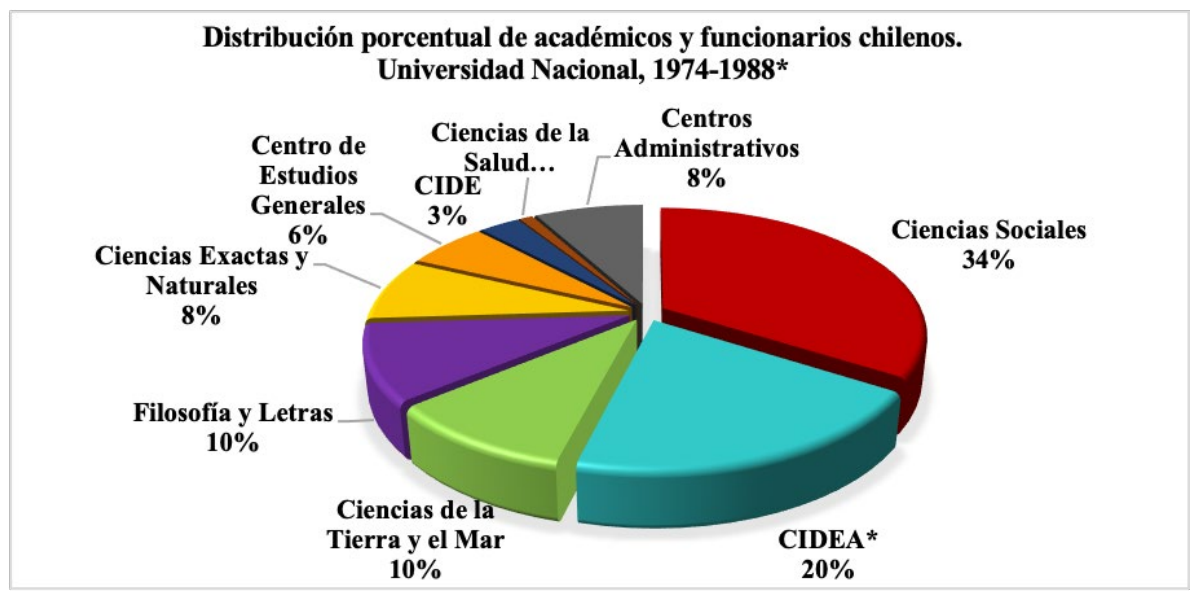

Nota: *Basado en registro de 89 académicos, académicas y funcionarios con más de 6 meses de trabajo continuo (Archivo Universitario, UNA).

La presencia de los chilenos en esta facultad tuvo la particularidad de que la mayoría de ellos estuvieron por periodos relativamente cortos, motivo por el que muy pocos dejaron aportes trascendentales a la UNA. Esta la fue la situación de Sara Astica, Bélgica Castro o Carmen Bunster que colaboraron en la Escuela de Artes Escénicas (EAE) por lapsos de apenas meses (ARH, UNA).

La excepción fue la actriz Marcia Maiocco, pues estuvo en la EAE por más de 23 años. Su trayectoria se definió por colaborar en la escena teatral costarricense en un momento importante de la historia de esta rama cultural, como integrante de proyectos tanto estatales como independientes (Cerdas, 2014). A este atributo, se sumó la característica de pertenecer a uno de los principales referentes del ámbito escénico de la década de los setenta, como lo fue el Teatro El Ángel, fundado en Chile por los actores Bélgica Castro, Alejandro Sieveking y Luis Barahona, que trasladaron el proyecto a Costa Rica.

En Arte y Comunicación Visual (EACV), entre sus primeros profesores estuvieron personajes como el arquitecto Juan Bernal Ponce, el escritor Franklin Quevedo y el pintor Julio Escámez. A este se le recuerda por el dominio en técnicas y por la rigurosidad de sus obras; su mayor 
aporte quedó plasmado en su amplia producción pictórica.

En la Facultad de Ciencias Sociales, los chilenos transitaron por varias unidades académicas: la Escuela de Sociología contó con 12 hombres y mujeres de esta nacionalidad; la mayoría ejercieron por más de dos décadas continuas. No obstante, el número no es representativo de la dimensión o alcances al mediano y largo plazo de sus acciones.

Le siguen la Escuela de Economía y el Instituto de Estudios del Trabajo con 4 personas cada una, así como la Escuela de Promoción y Planificación Social (EPPS) donde los suramericanos intervinieron desde su fundación, pues ahí estuvieron los sociólogos Natacha Molina y Arturo Sáez Chatterton ${ }^{3}$; además de la profesora Quiróz Martin. Esta última fue miembro de la Comisión Curricular de la EPPS, colaboró en la revisión de los alcances y limitaciones del plan de carrera, que dío como resultado la reestructuración de los perfiles profesionales en 1979

3 Ambos sociólogos formaron parte del primer grupo de chilenos exiliados que arribaron a Costa Rica, en octubre de 1973. Además de ellos, llegaron el periodista Ernesto Tapia y su esposa, Angélica Silva - ambos amigos de Eduardo Montecinos-, Ofelia Vílchez, Guillermo Pavez, Álvaro Díaz y el actor Patricio Arenas (La Nación, 11 de octubre 1973, p. 6A).
(EPPS, 1979). Por otra parte, trabajó para la Escuela de Trabajo Social y en el Instituto de Investigaciones Sociales de la UCR por 12 años (AUROL, UCR) en la elaboración de programas de carrera, la docencia y la investigación.

En la Escuela de Sociología tomó parte el filósofo Víctor Mourguiart Martínez, quien inició como profesor desde 1974 en el Ciclo Básico de la FCS de la UNA, departamento que dirigió entre 1977 a 1979 (ARH, UNA). En ese mismo año, se desempeñó como decano de la FCS por sustitución y posteriormente fue elegido para asumir el cargo en el periodo 1980-1985, quinquenio en el que impulsó proyectos de actualización de la unidad académica que representaba. Por ende, se implementaron planes direccionados a fortalecer el quehacer en sociología, en los que los chilenos aportaron desde la investigación y la extensión, campos prácticamente inexplorados en dicha unidad académica y en los que participó Cecilia Quezada Toro.

La profesora Quezada Toro fue nombrada directora de la Escuela de Sociología durante dos periodos consecutivos: 1981-1984 y 19851987 (ARH, UNA). Ella, al lado de Osvaldo Cazanga Solar, construyeron la totalidad de su trayectoria

206 Insertarse, adaptarse y construir: Participación del exilio chileno en las universidades estatales costarricenses a partir de 1974 Marcela Ramírez-Hernández

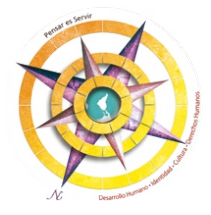


profesional en instituciones costarricenses, representando el segundo perfil generacional de académicos suramericanos. La primera, llegó a Costa Rica como esposa y madre; decidió emprender sus estudios en el claustro herediano, en tanto el profesor Cazanga arribó siendo estudiante de sociología, continuó sus estudios en la UCR y en el CSUCA.

Perteneciente a esta generación, está el historiador Mario Oliva Medina. La mayor parte de la trayectoria profesional ha sido desarrollada dentro de la UNA, donde ha ocupado diferentes cargos administrativos además de ser docente en la Escuela de Historia, la Facultad de Ciencias Sociales, el Instituto de Estudios Latinoamericanos (IDELA) y el Centro de Estudios Generales. No obstante, es en su producción escrita en donde es posible reconocer sus aportes de mayor trascendencia, que se traducen en varios libros y artículos publicados en revistas nacionales e internacionales, posicionándose como el chileno de este grupo generacional más prolífico.

En la Facultad de Filosofía y Letras, la Escuela de Literatura y Ciencias del Lenguaje (ELCL) contó con nueve chilenos en su cuerpo académico, entre ellos Juan Durán Luzio, Gastón Gaínza Álvarez y Carlos Santander
Tiraferri. El primero se dedicó exclusivamente a la UNA desde 1983, cuando le fue asignada una plaza de tiempo completo, cargo que ocupó por treinta y ocho años. En el tiempo que ejerció como académico, Durán Luzio se posicionó como un investigador destacado de la literatura costarricense y latinoamericana, se cuenta, entre sus colaboraciones, un acervo escrito con múltiples artículos y la publicación de seis libros (Durán, 2003).

Una escuela pionera en su naturaleza, sin precedentes en América Latina, fue la Escuela Ecuménica de Ciencias de la Religión (EECR), el primer espacio laico y universitario abocado a la preparación de estudiantes y a la investigación en teología. Dicha característica atrajo entre otros, a los chilenos Helio Gallardo y Pablo Richard. El primero de ellos comenzó como académico en la UCR desde 1974 en la Escuela de Filosofía y Estudios Generales; en la UNA, fue contratado en 1978 por la Escuela de Sociología y por la EECR, en esta última ejerció hasta 2010 (ARH, UNA).

Examinando la trayectoria de Gallardo, se reconoce que un peso significativo de su labor se materializa en una gran cantidad de obras escritas, que discurren entre tópicos como la filosofía, los derechos humanos, la 
antropología, metodologías de la investigación, la diversidad de género, la política latinoamericana, teología e inclusive, la ficción. Las dimensiones y diversidad de su escritura son su aporte más relevante, no solo a la academia costarricense, sino al pensamiento crítico latinoamericano.

En cuanto a Pablo Richard, se adscribió a la UNA en 1978. Específicamente en la Escuela Ecuménica, el teólogo ha sumado al fortalecimiento de la investigación y a las ramas de la eclesiología y la cristología. Al ser cofundador del Departamento Ecuménico de Investigaciones ${ }^{4}$ y con un haber de más de cuarenta libros y artículos publicados, se ha posicionado como uno de los principales teóricos de la teología de la liberación latinoamericana.

Por otra parte, la Facultad de Ciencias de la Tierra y el Mar ha sido una de la que ha obtenido mayores réditos de la participación de profesionales chilenos en sus filas. La Escuela de Ciencias Geográficas, particularmente, contó con el apoyo de cuatro académicos: Juan Humberto Cevo, contratado desde la creación de la

4 Se acota que muchos de los investigadores vinculados con el DEI desde la década de 1970 estuvieron también involucrados en la solidaridad con el pueblo chileno, como fueron Javier Solís, Armando Mora y el mismo Helio Gallardo. unidad académica y quien aportó significativamente en la articulación de los planes de carrera, Eusebio Flores Silva, Florencio Magallón y Miguel Morales.

Cevo fue autor del primer libro publicado por la editorial universitaria, titulado Modelos de análisis geográfico en Costa Rica (1974), a la vez que impulsó la creación de la Revista Geográfica de América Central publicada por primera vez en 1974. Por su parte, Eusebio Flores definió rutas importantes para el crecimiento de las ciencias geográficas. Una de sus tareas más significativas fue la pesquisa que culminó en el libro Geografía de Costa Rica, publicado por la UNED en 1979.

Además de los geógrafos antes reseñados, formó parte de la ECG Florencio Magallón, quien inició como colaborador en la estructuración de los planes de estudio desde setiembre de 1974. Posteriormente, en el segundo semestre de 1976, llegó Miguel Morales Álvarez, especialista en planificación urbano-regional (ARH, UNA). Morales, trabajó para la UNA en varias unidades académicas por un periodo de más de veinte años (ARH, UNA). Su producción abarca más de cuarenta escritos, entre publicaciones e investigaciones sobre diversas temáticas. 
En la Escuela de Ciencias Agrarias destacó el trabajo de Marcia Baraona Cockerell, especialista en fruticultura. Una parte de la experiencia adquirida por la chilena en las áreas de investigación y la docencia quedó materializada en la publicación de una serie de manuales didácticos sobre cultivos como la manzana y frutos rojos (Baraona, 1984), la piña y la papaya (Baraona y Sancho, 2000), fruticultura especial (Baraona, 1984), entre otros.

Otra unidad académica que contó con la colaboración de los chilenos fue la Escuela de Ciencias Ambientales (EDECA). Rodia Romero Sepúlveda se integró a la EDECA durante la estructuración de la unidad académica donde asumió responsabilidades en docencia y administración. Luego de encabezar la decanatura de la Facultad de Ciencias de la Tierra y el Mar entre 1979 y 1982, investigó al lado del geógrafo Miguel Morales los aspectos de ordenamiento espacial, dinámicas fronterizas y condiciones sociales en las regiones Brunca y Huetar Norte (Romero, Morales y Arias, 1988, 1989).

En la Facultad de Ciencias Exactas y Naturales, la Escuela de Ciencias Biológicas (ECB) contó con cinco académicos chilenos. El primero en integrarse a esta unidad académica fue Juan Bertoglia Richards en enero de 1975, quien, con solo un año de trabajo en Costa Rica, fue nombrado director para el periodo 1976-1978, en un momento de transición organizativa y de apertura del Bachillerato en Biología ${ }^{5}$. Entre sus labores destacaron la coordinación de la formulación del plan de estudios para el bachillerato y la licenciatura en la especialización de Biología Marina.

Según León Pacheco (diciembre 2012), la capacidad de gestión de Romero Sepúlveda sentó las bases del proyecto que daría origen a la Estación de Biología Marina de la UNA, ubicada actualmente en Puntarenas. Su quehacer incluyó la asignación de otros cargos jerárquicos como el Decanato de la Facultad de Ciencias Exactas y Naturales entre 1982 y 1985 , para regresar posteriormente a la dirección de la ECB en el periodo 1986-1989 (ARH, UNA).

En la coyuntura de la década de 1980, la ECB integró a dos biólogos: Jorge Cabrera Peña y Margarita Mora Jammet, que estuvieron a

5 Entre 1974 y 1976, funcionó el Departamento de Biología dedicado exclusivamente a impartir cursos a otras carreras y a formar docentes de ciclos básicos en Ciencias y Biología. Con la transformación de este departamento en Unidad Académica, se instauró la carrera propiamente dicha y se implementaron los programas para los grados de bachillerato $\mathrm{y}$ licenciatura (ECB, 1990, p. 8). 
cargo de cursos en acuacultura, limnología y ecología marina (L.C., comunicación personal, 2017). Finalmente, Ivette Inostroza Sotomayor inició su trabajo en la Facultad de Ciencias Exactas y Naturales durante esa misma década. En el periodo 1995 al 2000, la bióloga dirigió la ECB, momento en el que le correspondió concretar uno de los objetivos de más larga data de la unidad académica: la Estación de Biología Marina, a la cual dotaron de equipamiento y ampliaron su personal durante la gestión de Inostroza.

\section{Los chilenos en la Universidad de Costa Rica}

Como efecto del III Congreso Universitario, la UCR experimentó una reestructuración administrativa, reorganizó facultades y abrió nuevas unidades académicas. Dicha transición requirió, en su momento, de profesionales experimentados que colaboraran en la definición de nuevas carreras y áreas de investigación. En medio de este proceso institucional, llegaron los primeros profesores de Chile, introduciéndose en diversas unidades académicas, sumando un aproximado de noventa y ocho profesionales durante el periodo en estudio.

\section{Gráfico 2}

\section{Universidad de Costa Rica, 1974-1988*}

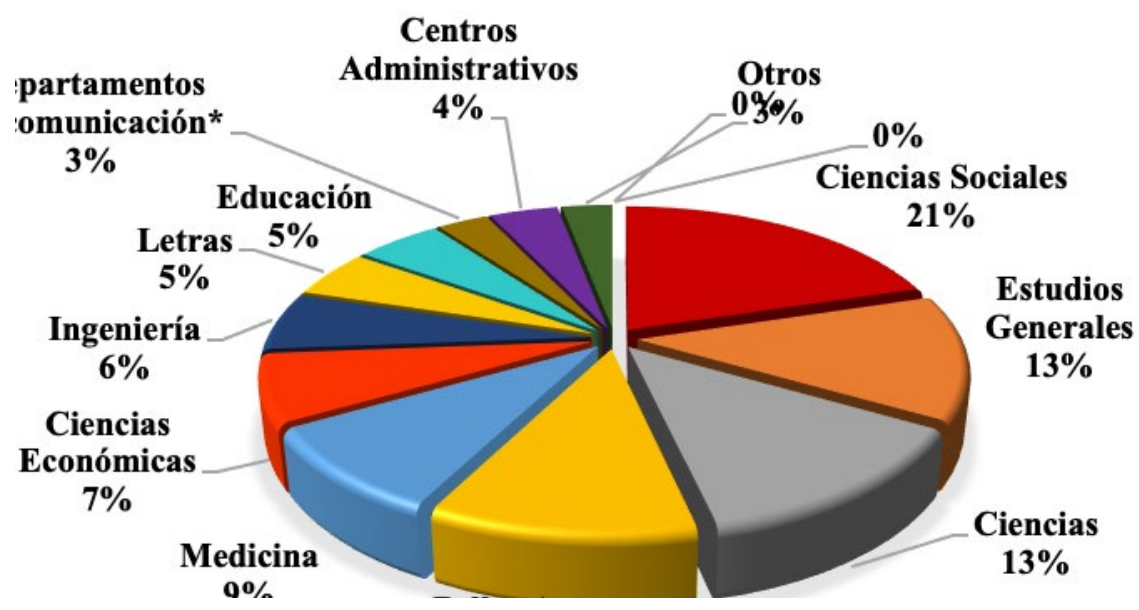

Nota: *Basado en registro de 98 Académicos, académicas y funcionarios con más de 6 meses de trabajo continuo (Archivo Universitario Rafael Obregón Loría y Recursos Humanos, UCR).

210 Insertarse, adaptarse y construir: Participación del exilio chileno en las universidades estatales costarricenses a partir de 1974 Marcela Ramírez-Hernández

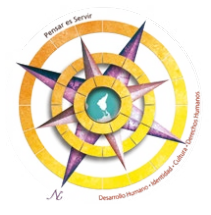


En esta universidad, la Escuela de Estudios Generales (EEG) tuvo un rol fundamental, pues fue el puente que permitió a muchos introducirse de manera efectiva en el sistema de educación superior. Mourguiart, Inostroza, Gaínza, Gallardo, Astica, entre otros, laboraron en un primer momento en esta unidad académica, situación que no era casual tomando en cuenta que la dirección estaba a cargo de don Isaac Felipe Azofeifa.

En la EEG resuenan los nombres de Marcelo Blanc Masías, Osvaldo Cazanga, Juan Reyes Meza y Raúl Torres. A este último se le debe la creación de los Seminarios Participativos en 1974 y de los cursos libres en 1980. Sobre el primer programa, este estuvo marcado por la innovación, pues la propuesta metodológica se basó en una serie de seminarios a cargo de varios profesores pertenecientes a diversas ramas del saber. Desde el principio de la cogestión educativa ${ }^{6}$, el objetivo era

6 De acuerdo con Torres, la cogestión educativa deriva de la metodología de la autogestión de los aprendizajes, en donde los actores que intervienen en el proceso pedagógico - profesores y estudiantes- trabajan desde la cooperación. Según esa lógica, a través de la constitución de un sentido comunitario en el que las opiniones y experiencias de cada participante son generadores de enseñanza, el estudiante asume la responsabilidad de construir al lado de sus pares y el profesor una metodología que potencie los aprendizajes a partir del hacer de los estudiantes copartícipes en sus procesos de enseñanza y aprendizaje.

En las disciplinas artísticas, la Facultad de Bellas Artes (FBA) de la UCR vio pasar por sus aulas al menos once chilenos como fueron los actores Patricio Arenas, Víctor Rojas Escobar, Bélgica Castro, al dramaturgo Alejandro Sieveking y Leonardo Perucci, así como al director musical Agustín Cullel Texeidó.

Entre los miembros destacados, estuvo Sara Astica, que desde la Escuela de Artes Dramáticas estableció enlaces entre la escena teatral y la enseñanza, tornándose indisociables una de la otra en su práctica profesional. Fue docente en otros espacios como la Compañía Nacional de Teatro y fundó el grupo Teatro Surco, establecido al lado de su pareja en 1977, el cual operó hasta el 2002 (Castellón, 2007). En honor al conjunto de su trayectoria teatral, la EAD propuso en mayo de 2007 - a dos años de la muerte de la actriz, en marzo de 2005 -la cátedra Sara Astica, dedicada a la enseñanza, la investigación y la difusión de los conocimientos teatrales desde un abordaje humanista e interdisciplinario (Vicerrectoría de Acción Social, mayo 2007).

cuestionamiento y la adecuación de las técnicas en clase (EEG, 1979). 
Dentro del ámbito de la gestión universitaria, resaltó Juan Katevas Lazarratu, director ejecutivo del Teatro Universitario (TU) desde 1977. Con su guía, se propusieron una serie de medidas encaminadas a atender no solo los problemas administrativos, sino también a impulsar la proyección del teatro hacia el resto de la comunidad universitaria y nacional, además de promover su profesionalización (Katevas, 1977). Como señala Manolo Montes (2001), en la dirección de Katevas empezó la "época dorada" del TU, pues en un lapso breve la entidad se posicionó como un referente de calidad dentro del circuito cultural josefino.

En la rama de las artes y las ingenierías, estuvo el grabador y arquitecto Juan Bernal Ponce. Desde marzo de 1975 fue contratado como profesor en la recién creada Escuela de Arquitectura de la UCR, durante una primera etapa marcada por la implementación de metodologías de enseñanza cercanas al pensar del chileno. Bernal Ponce, además de dedicarse a la creación artística, impartió cursos de grabado, el espacio social y principalmente el seminario "Ciudades e Historia", un repaso por los principios organizativos de la arquitectura en diversas civilizaciones y fases históricas.
La enseñanza y su trabajo como arquitecto lo motivaron al continuo estudio sobre San José, su transformación espacial, procesos de expansión y la confluencia de estilos arquitectónicos, dando pie a estudios sobre el devenir de la capital costarricense, cuyos resultados quedaron sistematizados en los textos para el curso Calidades del Espacio Arquitectónico (Bernal, 1983) y en escritos inéditos como Una biografía de San José (Bernal, 1991), ambos materiales acompañados por bosquejos que plasman edificios y viviendas josefinas de distintos periodos.

En el campo de las Ciencias Sociales, tomó parte una cantidad amplia de chilenos: diecinueve profesionales ubicados en diversas escuelas. Entre los espacios donde lograron mayor proyección, estaba la Escuela de Psicología, donde estuvieron Armando Campos Santelices y Dina Krauskopf Roger. En el caso del profesor Campos, su trayectoria en Costa Rica inició en 1975, fecha en que fue contratado por la UCR en el Departamento de Ciencias del Hombre como profesor extraordinario por tiempo completo, a cargo de los cursos de Psicología del Trabajo y Psicología Criminológica, áreas de estudio en los que sentó cátedra. En esos primeros años colaboró en la formulación de planes de carrera y

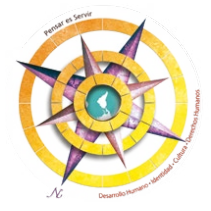


en la estructuración de la Escuela de Psicología (Comunicación personal, 2017). Sus aportes en las áreas de investigación, arriba acotadas, en la docencia y la gestión fueron reconocidas al ser nombrado profesor emérito en setiembre del 2005.

En cuanto a la Dra. Krauskopf, destaca hoy día por sus estudios en los campos de la educación y adolescencia, en las que la cientista implementó metodologías y teorías actualizadas e innovadoras en torno a las transformaciones físicas y psíquicas propias de esta etapa vital. El fortalecimiento de esta rama estuvo respaldado con producción escrita, como la publicación de 1982, Adolescencia y educación. Dicho texto se dirige a exponer cada una de las fases y procesos de adaptación de los adolescentes durante esta etapa transicional, por lo que recorre desde una perspectiva teórica y descriptiva, el impacto en las dimensiones familiares, físicas, sexuales y psicológicas (Krauskopf, 2007).

En el campo de las letras, incursionaron destacados profesores además del filósofo Helio Gallardo Martínez. En la Escuela de Filología, Lingüística y Literatura (EFLL) de la Facultad de Letras destacaron Enrique Margery Peña y Gastón Gaínza Álvarez. En literatura, Santander
Tirafferri laboró para esa misma unidad académica durante un lustro (AUROL, UCR).

La trayectoria de Margery Peña sobresale por haber sido uno de los principales estudiosos de la lengua y las mitologías indígenas costarricenses. Acreedor de múltiples publicaciones sobre lingüística, Margery analizó la construcción de los mitos, las formas de transmisión de la tradición oral entre grupos autóctonos y sus manifestaciones culturales. Dichos temas fueron difundidos a través de obras como Narraciones bocotás (Margery y Rodríguez, 1993), así como en los tres tomos de Estudios de mitología comparada indoamericana (Margery, 2003, 2006, 2010), cuyo primer tomo lo hizo acreedor del Premio Aquileo Echeverría en el 2003 en la categoría de Libro no ubicable (O'neal, 28 de junio 2011).

En esta misma Facultad, otro científico destacado fue Gaínza Álvarez, quien, aparte de su quehacer en filología, se introdujo en las artes y la crítica teatral con la publicación de la revista Escena, de la cual es cofundador y exintegrante del Consejo Editorial junto a Juan Katevas y Víctor Valembois (Montes, 2011). Fue miembro de importantes proyectos y su producción intelectual 
está compuesta por más de 60 publicaciones en varias revistas académicas, abordando temas como la crítica literaria, teatral y de arte; la semiótica, retórica y lingüística. En 2017 sus aportes fueron reconocidos con la creación de la Cátedra Conmemorativa Gastón Gaínza Álvarez: Identidad y Culturas (Vicerrectoría de Docencia, setiembre 2017), que mantiene como propósito generar espacios para el diálogo en torno a temas vinculados con las identidades y las problemáticas latinoamericanas (Vicerrectoría de Docencia, setiembre 2017).

En disciplinas asociadas con las Ciencias Económicas hubo aproximadamente siete chilenos, de los cuales cuatro estuvieron dedicados a la Carrera de Administración Aduanera, gestionada por la Escuela de Administración Pública. En esta rama resuena el nombre de Luis Azúa Torres. Exiliado en Costa Rica, se instaló como asesor en la Dirección Nacional de Aduanas del Ministerio de Hacienda, sitio en el que detectó en los funcionarios la ausencia de capacitación formal en administración de aduanas. Para sanear esta falencia, Azúa propuso al Ministerio implementar un programa de educación permanente (Azúa, 1974-1975, p. 10). La propuesta de capacitación fue acogida por el
Centro de Investigación y Capacitación en Administración Pública (CICAP) de la UCR en 1978, dio así inicio a la carrera de Administración Aduanera (Azúa, comunicación personal, 29 de enero 2018).

Las colaboraciones de Azúa se extienden a la publicación de sistematizaciones tributarias, entre ellas Repertorio para la clasificación arancelaria de mercancías en Centroamérica (1979), un índice alfabético de nomenclaturas de productos de exportación e importación según rama productiva, que facilitó la asignación de impuestos y aranceles (Azúa, comunicación personal, 2018). Posteriormente publicó Arancel de aduanas (1989), el que establecía gravámenes integrados para unificar los impuestos internos a la importación.

Finalmente, la UCR acogió en sus aulas a varios y reconocidos galenos, que ocasionalmente se dedicaron a las labores de la docencia, las cuales se vieron enriquecidas por la práctica y el trabajo de investigación. Según datos de los archivos institucionales, por dicha Facultad pasaron al menos diez especialistas de la salud dentro del periodo en estudio, abocados a la salud pública, la epidemiología, la pediatría y la odontología, entre otros, pero que

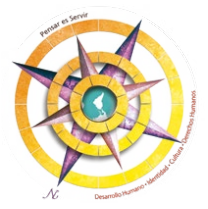


laboraron en su mayoría, por periodos menores a los diez años.

Tomando en consideración estas especificidades, se mencionará los doctores Hugo Behm Rosas y Jaime Serra Canales, en tanto llevaron a cabo investigaciones y colaboraciones de peso en el ámbito de la medicina. El primero de ellos era un referente en la salud pública a nivel latinoamericano, con una vasta trayectoria como galeno e investigador, mientras el segundo formó parte de un plan de autogestión comunitaria local sin precedentes.

En torno al doctor Behm Rosas, este es reconocido como uno de los principales impulsores de la Salud Pública en Chile. Consultor de CELADE en Chile y posteriormente en Costa Rica, estuvo a cargo del proyecto Investigación de la Mortalidad Infantil en América Latina (Comisión Económica para América Latina y el Caribe, 11 de abril 2011), del cual se derivaron entre 1976 y 1978, quince fascículos que abordan el tema de la esperanza de vida en niños y niñas en relación con variables socioeconómicas como condicionantes de la salud ${ }^{7}$.

7 Esta serie está compuesta por quince fascículos titulados La mortalidad en los primeros años de vida en países de América Latina. Explora entre 1965 y 1972 los indicadores y realidades de Costa Rica, Argentina, Guatemala,
Por su parte, Serra Canales también tuvo un paso breve por la Facultad de Medicina que no se prolongó más de un año (AUROL, UCR); no obstante el compromiso del galeno con las comunidades y la salud, lo definen como un referente del exilio chileno. Exiliado desde 1974 estableció contacto con el doctor Juan Guillermo Ortiz, encargado del programa Hospital sin Paredes en el cantón de San Ramón en Alajuela, fundando entre 1971 y 1973.

Establecido como un programa de autogestión comunal e independiente al sistema estatal de salud, el Hospital sin Paredes ofrecía a la comunidad ramonense atención de especialistas en la obstetricia, pediatría, odontología, entre otros. Serra se integró en esta primera fase, aportando desde la pediatría y la salud pública, dando seguimiento a pacientes e interviniendo en asuntos administrativos, impulsando las iniciativas y propuestas surgidas desde la comunidad (Ortiz y Serra, 1988; Serra y Serra, 2015).

\section{Conclusiones}

El paso de los chilenos por las universidades costarricenses tuvo

Honduras, Nicaragua, El Salvador, Paraguay, Bolivia, Colombia, Ecuador, Chile, Perú y República Dominicana. 
características específicas manifiestas en la calidad de sus aportes, sus perfiles, su capacidad de adaptación y también, en la cantidad presente en los recintos universitarios. En relación con las profesiones y campos de acción, es posible reconocer que varios de ellos provenían del sector educativo, pero hubo también funcionarios estatales que encontraron en las universidades locales un espacio de proyección profesional alterno. Dicha heterogeneidad contribuyó a nutrir la circulación y producción de saberes en las disciplinas donde tuvieron mayor protagonismo.

Como se indicó en páginas anteriores, si bien el traslape de los sucesos acontecidos en los contextos chileno y costarricense intervino en la recepción de los académicos, también hubo otro factor de incidencia que posibilitó la inserción a las instituciones universitarias: la existencia de cierto capital simbólico históricamente construido a través de redes sociales tejidas entre intelectuales desde el largo plazo, por medio de relaciones diplomáticas, artísticas y educativas. Estas redes permanecieron activas durante los años setenta y tuvieron entre sus miembros a destacados personajes que cumplieron un rol primordial en la inserción de los chilenos al mundo educativo.
Otro de los motivos que posibilitaron la retroalimentación entre sujetos y espacios, fue el hecho de que varios de los chilenos, al momento de llegar a Costa Rica, poseían diferentes tipos de recursos intelectuales, que sirvieron como puntos de anclaje con la sociedad receptora y a través de los cuales pudieron establecer cierto margen de negociación sobre los términos y condiciones de su participación social.

A partir de los resultados de esta investigación, se asume, entonces, el exilio como un fenómeno potenciador de las capacidades intelectuales, en tanto el entorno receptor brindó las posibilidades para el emprendimiento de iniciativas. Debe considerarse que la labor de los chilenos en la academia costarricense puede ser traducida como el esfuerzo por integrarse dentro de las dinámicas institucionales, sociales e históricas de Costa Rica, a través de la producción y sistematización de conocimientos.

Finalmente, señalamos que las características de una parte de la producción escrita y de la trayectoria profesional en general, demuestra que muchas de las personas reseñadas en este texto emplearon sus deberes laborales y sus profesiones como herramientas de reconocimiento de la sociedad costarricense.

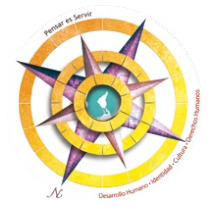


De ello queda prueba en la publicación de estudios en torno a una amplia gama de tópicos, dirigidos a analizar las particularidades de la realidad y la historia costarricense, a sus personajes y espacios.

\section{Bibliografía}

Archivo Chile. (15 de octubre 2005). La dictadura y la educación. http://www. archivochile.com/edu/doc_analit/ est_doc_analit00015.pdf

Azúa,L. (1974). La capacitación profesional de los funcionarios aduaneros. Dirección General de Aduanas, Ministerio de Hacienda. Mimeografiado.

Azúa, L. (1979). Repertorio para clasificación arancelaria de las mercancías en Centroamérica: índice alfabético de las nomenclaturas aduaneras. Imprenta y litografía San Martín

Azúa, L. (1989). Arancel de Aduanas. CONDECOR

Bernal, J. (1983). Textos para el taller. Compilación de escritos: Curso Calidades del Espacio Arquitectónico. Escuela de Arquitectura, UCR.

Bernal, J. (1991). Una biografía de San José. Mimeografiado.

Camacho, D. (2012). La autonomía universitaria, la vigencia del III Congreso Universitario y una obligada referencia a Rodrigo Facio. Revista de Ciencias Sociales 138(4), 11-20.

Castellón, M. (2007). Trayectoria teatral de un exilio chileno: Grupo Surco [Tesis para optar al grado de Magister
Artium]. Sistema de Estudios de Posgrado, Universidad de Costa Rica.

Cerdas, D. (2014). Escuela de Arte Escénico. EUNA.

Comisión Económica para América Latina y el Caribe. (11 de abril). Hugo Behm Rosas, la coherencia y el compromiso. https://www.cepal.org/celade/ noticias/noticias/5/43335/

Durán, J. (2003). Senderos de identidad. Editorial Costa Rica.

Escuela de Ciencias Biológicas. (1990). Plan de Estudios Carreras Bachillerato en Bilogía Tropical y Licenciatura en Biología Tropical con énfasis en Manejo de recursos naturales. ECB, UNA.

Escuela de Estudios Generales. (1979). Seminarios Participativos. Escuela de Estudios Generales, Universidad de Costa Rica.

Escuela de Promoción y Planificación Social. (1979). Perfiles profesionales del planificador.

Escuela de Psicología. (2017). Docentes eméritos: Armando Campos Santelices. UCR. https://www.psico. ucr.ac.cr/index.php/es/personal/docentes-emeritos\#dr-armando-campos-santelices

García, R. (7 de noviembre 1999). Del sur al sur. La Nación, 6 http://wvw.nacion. com/dominical/1999/noviembre/07/ dominical6.html

García, B., Ortíz, B. (2012). Conceptualizaciones sobre el trabajo académico del profesor universitario. http:// die.udistrital.edu.co/sites/default/ files/doctorado_ud/publicaciones/ 
conceptualizaciones_sobre_trabajo_academico_del_profesor_universitario.pdf

Garretón, M. (2005). Las ciencias sociales en Chile. Institucionalización, ruptura y renacimiento" Social Sciences in Latin America, 44(Special Issue). http:// www.manuelantoniogarreton.cl/documentos/07_08_06/sociales.pdf

González, P. (2008). La sociabilidad y la historia política. Nuevo Mundo Mundos Nuevos. https:/DOI: 0.4000/ nuevomundo. 24082

Katevas, Juan. (2091). TU (1/1). Teatro Universitario. Anteproyecto Repertorio y presupuesto para el año 1977 del Teatro Universitario.

Krauskopf, D. (2007). Adolescencia y educación. EUNED.

Montes, M. (2001). Teatro Universitario 1977-1986: La época dorada. Revista Escena, 47(1-2), 141-158.

Núñez, B. (1974). Hacia la universidad necesaria. UNA.

O’Neal, Katzy. (28 de junio 2011). Enrique Margery Peña: Lingüista de grata memoria. Oficina de Divulgación e Información, UCR. https://www. ucr.ac.cr/noticias/2011/06/28/enrique-margery-pena-linguista-de-grata-memoria.html

Pacheco, F. (diciembre 2012). Don Juan Bertoglia Richards, forjador de las ciencias marinas en la Universidad Nacional de Costa Rica. Revista de Ciencias Marinas y Costeras, 4. 9-12.
Romero, R., Arias, A., Morales, M. (1989). La cuestión fronteriza en la región Brunca: Algunos elementos para discusión. UNA, EPPS.

Serra, Jaime y Ramírez, Gonzalo. (Junio-setiembre 1988). La experiencia del programa de salud en la comunidad "Hospital sin Paredes". Revista de Ciencias Sociales de la Editorial de Costa Rica, 40 - 41, 101-120.

Serra Stepke, Soledad y Serra Stepke, Ignacio. (2015). Biografía del profesor Dr. Jaime Serra: de la Hepatitis viral a la Salud Integral. Cuadernos Medicina Social, 55 (3 y 4), 175-186. https://www.researchgate.net/publication/309617472_Biografia_del_ profesor_Dr_Jaime_Serra_de_la_ Hepatitis_viral_a_la_Salud_Integral.

Universidad Estatal a Distancia. Junta Universitaria. Acta n. 126. 31 de enero 1979. https://www.uned. ac.cr/conuniversitario/images/actas/1979/00126-79.pdf

Universidad Nacional. Actas Comisión Organizadora Ad-Hoc. Acta n. 66. 22 de noviembre 1973 .

"Universitarios forman Comité de Solidaridad con Chile". (6 de julio 1974). Libertad.

Vicerrectoría de Docencia. (27 de mayo 2013). Creación de la Cátedra Sara Astica. Resolución VD-R-8958-2013.

Vicerrectoría de Docencia. (4 de setiembre 2017). Creación de la Cátedra Conmemorativa Gastón Gaínza. Resolución VD-R-9839-2017.

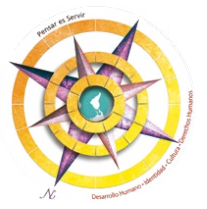

